\title{
INVESTIGAÇ̃̃O DOS FATORES CONDICIONANTES DO CAPITAL DE GIRO EM MICRO E PEQUENAS EMPRESAS: UMA ABORDAGEM POR GRUPOS ESTRATÉGICOS ${ }^{1}$
}

\author{
INVESTIGATION OF CONDICTIONAL FACTORS OF THE CAPITAL OF TURN IN \\ MICRO AND SMALL COMPANIES: A BOARDING FOR STRATEGICAL GROUPS
}

\author{
Lucas Maia dos Santos ${ }^{2}$ \\ Marco Aurélio Marques Ferreira ${ }^{3}$
}

\begin{abstract}
Resumo: De modo geral, as micro e pequenas empresas (MPEs) são atrativas do ponto de vista de rentabilidade, porém, devido às deficiências na gestão financeira de curto prazo, operam em alto risco de liquidez. Nesse contexto, o presente estudo teve como objetivo identificar e analisar o desempenho de agrupamentos de MPEs, de acordo com as metodologias e práticas na condução da gestão de capital de giro. Neste trabalho, que utilizou abordagem quantitativa exploratória, foram entrevistados 172 proprietários de MPEs, o que, por meio de análise fatorial seguida de análise de cluster, resultou na identificação de três grupos com características distintas, baseando-se em aspectos limitantes do risco de liquidez, sendo eles categorizados como: baixo risco, médio risco e alto risco. Embora se observasse um grupo com baixo risco de liquidez, fica evidente a importância da gestão financeira de curto prazo na região, visto que a manutenção de uma correta gestão está longe de ser unânime, em razão da presença de aproximadamente $30 \%$ das empresas classificadas nos grupos de médio e alto risco de liquidez. Por fim, a identificação de empresas com estratégias semelhantes com as melhores práticas utilizadas na gestão financeira de curto prazo pode ser um instrumento para aplicação nas empresas dos agrupamentos de médio e alto risco de liquidez, visto que alguns fatores condicionantes do risco de liquidez foram identificados.
\end{abstract}

Palavras chaves: risco de liquidez, micro e pequenas empresas, análise de cluster

\begin{abstract}
Usually, micro and small businesses (MSBs) are attractive for their profitability, but, because of some deficiencies in short term financial administration, they work in a high liquidity risk. In this context, this paper aimed to identify and analyze the acting of MSB groups according to the methodologies and practices in the working capital conduction, taking as reference the county of Viçosa, MG. In this paper, in which it was used the exploratory quantitative approach, 172 MSBs owners were interviewed, and this fact, through the factorial analyses followed by the cluster analyses, resulted the identification of three groups with distincts characteristics, basing in restrictive aspects of liquidity risk in these business: low risk, medium risk, and high risk. Despite of the fact that it was noticeable a low liquidity risk group, it is evident the importance of the short term financial administration in the region, since the maintenance of a correct administration is far from being unanimous due to the classification of nearly $30 \%$ of the businesss in medium and high liquidity risk. To finish, the identification of businesses with similar strategies and the best practices used in the short term financial administration can be an applicable instrument in the businesses classified in medium and high liquidity risk, since some conditioning factors of the liquidity risk were identified.
\end{abstract}

Keywords: liquidity risk, micro and small business, cluster analyses.

\footnotetext{
${ }^{11}$ Artigo Recebido em 30.07.2008 . Revisado por pares em 05.12.2008 . Recomendado em 05.02.2009 por Denise Del Pra Netto Machado (editora). Publicado em 02.03.2009.

Organização Responsável pelo periódico: Universidade regional de Blumenau - FURB - www.furb.br/rn
}

\footnotetext{
${ }^{2}$ Graduando em Administração Universidade Federal de Viçosa - admlucasmaia@yahoo.com.br

${ }^{3}$ Professor do Departamento de Administração da Universidade Federal de Viçosa - marcoaurelio@ufv.br
} 


\section{INTRODUÇÃ̃O}

As micro e pequenas empresas (MPEs) compõem importante parcela da economia nacional e mundial. Conforme SEBRAE (2005), essas empresas, no Brasil, respondem por $99,2 \%$ do número total de empresas formais, por $57,2 \%$ do total de empregos e por $26 \%$ da massa salarial. Um dos papéis designados a elas é a oferta de produtos e serviços demandados pela sociedade que só podem ser rentáveis se comercializados em pequena escala.

Apesar de constituírem um dos pilares da economia nacional, segundo SEBRAE (2005), aproximadamente 60\% das MPEs morrem até o quarto ano de existência. De acordo com recente estudo sobre fatores condicionantes e taxa de mortalidade das MPEs, realizado pelo SEBRAE (2007), os próprios empresários apontaram problemas na administração de capital de giro como um importante fator dessa mortalidade.

Em razão das suas peculiaridades, as MPEs enfrentam problemas bem específicos, em geral, diferentes ou em proporções dessemelhantes quando comparados àqueles vivenciados pelas grandes empresas. Destaca-se que, às vezes, as MPEs são atrativas do ponto de vista de rentabilidade, mas, devido às deficiências na gestão financeira de curto prazo, operam em alto risco de liquidez, o que as deixam suscetíveis a imprevistos comuns à natureza dos negócios. Isso instiga estudos voltados à análise da gestão de capital de curto prazo nessas empresas, como proposto neste trabalho.

Por sua vez, problemas como esses impactam o desenvolvimento local e regional em razão da grande empregabilidade desse setor, o que sugere ações de investigação das causas de limitação financeira, principalmente no que tange à gestão de capital de giro, apontada como grande fator de restrição entre essas organizações e que remete à forma de gestão do sócio-proprietário das MPEs. Resnik (1990) aponta como conseqüências da limitação financeira: a perda da confiança e da moral do empresário; a elevação dos preços ou sua drástica redução, em ato de desespero do empresário, colocando-os fora da realidade do mercado; a má remuneração de funcionários; o não-pagamento de impostos; e a falta de fundos para sanar contingências.

Dentro desse contexto, este trabalho foi conduzido com o objetivo de identificar e analisar o desempenho de agrupamentos de micro e pequenas empresas, de acordo as metodologias e práticas na condução da gestão de capital de giro; escolheu-se como delimitação regional o município de Viçosa-MG.

\section{ADMINISTRAÇÃO FINANCEIRA DE CURTO PRAZO EM MPES}

Segundo Braga et al., (2004), a falta de recursos financeiros é apontada como uma das maiores dificuldades com que convivem as MPEs; por sua vez, este é um fator que limita os investimentos necessários para que essas empresas se desenvolvam ou, até mesmo, sobrevivam.

De acordo com Monteiro (2002), as pequenas organizações possuem capacidade e recursos restritos, especialmente quanto ao capital (empréstimos difíceis e fluxo de caixa reduzido) e à formação daqueles que atuam na administração e assessoria da empresa.

Matias e Lopes Júnior (2002) afirmam que a maior dificuldade das MPEs é o insuficiente preparo gerencial dos proprietários ou dirigentes, destacando-se que as estratégias dessas empresas são estabelecidas confiando puramente em informações e experiências vivenciadas pelos seus administradores, confirmando um fator predominante que influencia diretamente nas decisões financeiras de curto prazo da empresa. Além disso, as dificuldades começam no dia-a-dia do proprietário, que, por falta de condições para contratação de pessoas 
eficientes e de confiança para a gestão do negócio, acaba acumulando funções, culminando no inadequado desempenho das atividades gerenciais.

Além dos problemas já citados, são listadas a seguir outras questões que dificultam a gestão financeira nas micro e pequenas empresas:

- A falta de recursos financeiros e dificuldades na obtenção de créditos, financiamentos e investimentos por parte de terceiros, porque investidores raramente sentem-se atraídos por empresas de menor porte (CHÉR, 1990);

- A manutenção de maus pagadores, falta de disciplina, responsabilidade e organização (CHÉR, 1990).

- A falta de controle que ocasiona dificuldade para análise e avaliação de decisões tomadas, quando da exposição da empresa ao ambiente de negócios (GAZZONI, 2003).

- O "efeito sanduíche" - situação de perda do poder de barganha no qual as micro e pequenas empresas acabam ficando quando os preços de compra são impostos pelos fornecedores e os preços de venda, pelos clientes - ocasionado pelo relacionamento freqüente com grandes fornecedores ou grandes clientes (CHÉR, 1990).

Braga et al., (2004) entendem que o capital de giro insere-se no contexto das decisões financeiras de curto prazo, envolvendo a administração de ativos e passivos circulantes. Segundo Pereira Filho (1998), o ativo circulante consiste de quatro componentes principais: caixa, títulos negociáveis, estoques e contas a receber. Normalmente, contas a receber e estoques são os itens mais representativos do ativo circulante, de modo que outros valores a receber e despesas pagas antecipadamente tendem a não ser representativos em termos de valores.

Souza (2007) afirma que o ativo circulante representa o valor dos recursos aplicados pela empresa para movimentar seu ciclo operacional, que compreende o período de tempo que vai desde a entrada da matéria-prima no estoque da empresa até a venda dos produtos elaborados e respectivo recebimento.

Vários autores definem o ciclo operacional como o montante de tempo que vai do ponto em que a empresa coloca material e trabalho no processo de produção, até o momento em que o dinheiro da venda do produto acabado resultante é efetivamente recebido. $\mathrm{O}$ ciclo operacional também pode ser deduzido pela soma do período médio de estocagem e recebimento dos clientes. Dentro do ciclo operacional tem-se o ciclo de caixa, definido como montante de tempo em que o caixa da empresa está imobilizado entre o pagamento dos insumos de produção e a cobrança do pagamento da venda do produto acabado resultante (SOUZA, 2007; PEREIRA FILHO, 1998; LEMES JUNIOR, 2005).

Pereira Filho (1998) menciona ainda que paralelamente ao ciclo operacional ocorre o financiamento concedido pelos fornecedores, a partir do momento da compra. Até o momento do pagamento aos fornecedores a empresa não precisa se preocupar com o financiamento, o qual é automático. Se o prazo médio de pagamento de fornecedores for superior ao prazo médio de estocagem, então os fornecedores financiarão também uma parte das vendas da empresa.

De acordo com Serrasqueiro e Raposo (2002), a boa política de capital de giro é elaborada para minimizar o tempo entre desembolsos de caixa com materiais e recebimentos das vendas. Para esse autor, a disponibilidade de caixa deve existir pelas seguintes razões:

- Obter descontos dos fornecedores, tendo em vista que o custo de não utilizar os descontos é alto.

- Ajudar a empresa a manter sua classificação de crédito, mantendo sua liquidez corrente e sua liquidez seca alinhadas com as de outras empresas de seu setor.

- Aproveitar oportunidades de negócios favoráveis, como promoções especiais dos fornecedores ou a chance de adquirir outra empresa. 
- Enfrentar emergências como greves, incêndios ou campanhas de marketing dos concorrentes e também para suportar quedas sazonais ou cíclicas no nível de atividade.

Toda empresa precisa buscar um nível satisfatório de capital de giro, de maneira a garantir a sustentação de sua atividade operacional. Como afirmam Hopp e Leite (1989) e Pereira Filho (1998), para se manter em equilíbrio financeiro, uma opção da empresa é financiar suas necessidades variáveis com dívidas de curto prazo, utilizando os recursos de longo prazo para financiar todas suas necessidades financeiras permanentes.

\subsection{Classificação organizacional}

As classificações são resultantes de um processo de agrupamento, decorrente de alguma metodologia empírica ou estatística específica. As mais comuns são resultantes de processos estatísticos de agrupamento, visto o caráter de confiança atribuído a essa metodologia, amparada em vasta literatura. Nessa ótica, uma classificação decorrente de processo de agrupamento deve ser vista como um sistema tipológico, comprometido com certos componentes, que minimizem a subjetividade do pesquisador, atendendo a requisitos teóricos sustentáveis.

De acordo com Schendel e Hofer (1979), toda classificação está pautada em algum atributo que permita descrever as características fundamentais das unidades organizacionais, no que diz respeito às suas competências, aos seus recursos e às suas oportunidades e ameaças, visando sua adequação ao ambiente organizacional. É dessa forma que, neste trabalho, buscou-se classificar as MPEs de acordo com as características da gestão de capital de giro, identificando variáveis condicionantes de problemas de liquidez nessas empresas.

Segundo Chrisman et al. (1988), uma classificação deve atender aos atributos de diferenciação, identificação, generalização e recuperação da informação. A diferenciação pode ser considerada como caráter de distinção entre cada um dos agrupamentos, enquanto a generalização diz respeito à possibilidade de realização de estudos e inferências para todas as unidades do agrupamento. A identificação está associada à possibilidade de realizar inferências pontuais sobre as unidades produtivas singulares de um agrupamento, sem perder a consistência com o grupo. Finalmente, é necessário que um sistema de classificação não apenas acumule informações, mas permita também seu armazenamento e sua recuperação para fins de análise (CHRISMAN et al., 1988).

\subsection{Abordagem dos agrupamentos estratégicos}

De acordo com Athanassopoulos (1995), agrupamentos ou grupos estratégicos podem ser definidos como um conjunto de empresas que atua dentro do mesmo ambiente industrial, segue estratégias semelhantes e exibe características simétricas em várias dimensões. Nessa ótica, grupos estratégicos podem ser identificados e classificados em todos os setores, em que um número significativo de organizações participa, a exemplo dos três agrupamentos obtidos no presente trabalho. De acordo com a tendência de risco de liquidez, as empresas analisadas foram divididas nos seguintes grupos: alto risco, médio risco e baixo risco. Tendo em vista que o risco de liquidez não é uma opção estratégica, neste caso, os agrupamentos serão diferenciados somente pelas características simétricas de análise do risco de liquidez, excluindo-se a análise por estratégias semelhantes.

A análise dos grupos estratégicos é precedida da composição dos grupos, o que é realizado em função das similaridades e diferenças entre as organizações. Nesse sentido, os benefícios de uma análise condicionada pela composição de grupos estratégicos estão ligados à exploração das características físicas e comportamentais das organizações que compõem um

Revista de Negócios, ISSN 1980-4431, Blumenau, v. 13, n. 3, p. 51 - 66, Julho/Setembro 2008. 54 
mesmo escopo estratégico, visando interpretar a razão de suas diferenças em dado atributo. Esse atributo pode ser desempenho financeiro, crescimento operacional, parcela de mercado ou eficiência. No presente estudo, a diferenciação dos grupos se deu pela investigação de problemas de liquidez, realizando-se ilações sobre as empresas com comportamentos semelhantes dentro de um determinado grupo de MPEs.

A maior crítica à abordagem de grupos estratégicos está na orientação empírica e nos atributos discricionários, que compõem a escolha das variáveis estrategicamente pertinentes à construção da análise de agrupamento (BARNEY; HOSKISSON, 1990).

De acordo com Athanassopoulos (1995), a crescente utilização da análise de grupos estratégicos chamou a atenção para o uso de métodos quantitativos, apropriados à composição dessa abordagem. Essas metodologias incluem o uso de teoria dos jogos (KUMAR et al., 1990), análise multivariada (DUYSTERS; HAGEDOORN, 1995), otimização (LAWLESS; ANDERSON, 1996), regressão linear (GORDON; MILNE, 1999) e a construção de fronteiras de eficiência (SCHEFCZYK, 1993; FIEGENBAUM; THOMAS, 1994; DAY et al., 1995; ATHANASSOPOULOS; BALLANTINE, 1995).

\section{METODOLOGIA}

O presente trabalho foi realizado no município de Viçosa - MG, localizado na Zona da Mata mineira. A escolha da região foi motivada pela alta concentração de MPEs e pela relativa dispersão entre os diversos setores que movimentam a economia local, sobretudo aqueles ligados ao comércio e à prestação de serviços. Para realização deste estudo, foram aplicados questionários, pessoalmente, em 172 proprietários de MPEs em funcionamento.

Para coleta de dados foram utilizadas as seguintes técnicas de pesquisa qualitativa em ciências sociais: pesquisa bibliográfica e aplicação de questionários. Na estratégia de coleta de dados utilizou-se amostra aleatória simples, estatisticamente significativa, com um erro máximo associado de 7,3\%. Na elaboração do questionário foi utilizada a técnica do balanço falado, citado por Kassai e Kassai (2001), que é um processo de planejamento empresarial para coleta de informações financeiras como uma alternativa mais próxima da realidade, em contrapartida aos relatórios financeiros elaborados por essas empresas.

Este trabalho teve caráter exploratório e descritivo. Quanto à abordagem do problema e operacionalização das variáveis, a pesquisa foi quantitativa no levantamento e tabulação dos dados e qualitativa na análise e comparação desses dados para identificar as especificidades do objeto de pesquisa, bem como os fatores limitantes da administração de capital de giro.

\subsection{Análise fatorial}

Após a eliminação de outliers e dos questionários inconsistentes, pelo procedimento de Análise Exploratória de Dados AED, efetuou-se a análise fatorial com as variáveis mais relevantes do estudo, a fim de obter número reduzido de fatores estratégicos. Segundo Hair (2005), em termos gerais, a análise fatorial aborda o problema de analisar estruturas das interrelações entre grande número de variáveis, definindo um conjunto de dimensões latentes comuns, denominado "fator". Para o cálculo dos fatores, o procedimento dos componentes principais foi utilizado, por ser amplamente empregado na maioria dos estudos e ser o método mais adequado - quando a preocupação principal é a previsão ou a obtenção de número mínimo de fatores necessários - para explicar a máxima variância representada pelo conjunto original das variáveis.

Em geral, a análise fatorial deve ser realizada adotando-se um conjunto de procedimentos estatísticos, sendo eles: a) determinação das correlações entre as variáveis 
selecionadas; b) extração de fatores significativos e necessários à representação dos dados; c) transformação dos fatores, por intermédio do procedimento de rotação, como forma de tornálos interpretáveis; e d) construção dos escores fatoriais.

$\mathrm{Na}$ determinação das correlações, é possível excluir aquelas variáveis que não admitem relações com as demais. A segunda etapa consiste na ponderação e seleção do número de fatores necessários à explicação do conjunto de dados, bem como do método de cálculo para sua obtenção. $O$ procedimento mais comum tem sido a utilização dos componentes principais para o cálculo dos fatores. $\mathrm{Na}$ terceira etapa, rotação dos componentes principais, é comum a utilização do método VARIMAX, a fim de minimizar o número de variáveis altamente relacionadas com cada um dos fatores, facilitando a interpretação dos resultados. O método VARIMAX tem sido muito bem-sucedido, como abordagem analítica para a obtenção de rotação ortogonal de fatores (HAIR, 2005; MAROCO, 2003).

A quarta etapa consiste na obtenção dos escores fatoriais, para cada unidade presente na amostra. $\mathrm{O}$ escore fatorial é resultante da multiplicação do valor padronizado da variável i pelo coeficiente do escore fatorial correspondente. $\mathrm{O}$ j-ésimo fator, $\mathrm{Fj}$, pode ser obtido, empregando-se a Equação (1), adaptada de Manly (1986):

$$
F_{j}=\sum_{i=1}^{p} W_{j i} X_{I}=W_{j 1} X_{1}+W_{j 2} X_{2}+\ldots+W_{j p} X_{p}
$$

em que os $W j i$ são os coeficientes dos escores fatoriais; e $p$ é o número de variáveis.

\subsection{Análise de cluster}

Após a redução dos fatores, foi realizada a análise de cluster, que tem como objetivo agrupar objetos ou indivíduos segundo suas características fundamentais, formando grupos ou conglomerados semelhantes. De acordo com Hair (2005), as organizações em cada conglomerado tendem a ser semelhantes entre si, porém diferentes das demais pertencentes a outros conglomerados. Por ser este o mesmo propósito perseguido pela análise de agrupamentos estratégicos, torna-se, portanto, o procedimento multivariado mais adequado aos objetivos do trabalho.

Neste trabalho, foi utilizado o método não-hierárquico K-Means. Segundo Maroco (2003), nesse procedimento é realizada a partição inicial dos sujeitos em $K$ clusters definidos pelo pesquisador e, em seguida, procede-se ao cálculo dos centróides para cada um dos $K$ clusters e o cálculo da distância euclidiana dos centróides a cada sujeito na base de dados. $\mathrm{O}$ emprego do quadrado da distância euclidiana, como medida de semelhança entre as observações, é expresso matematicamente por:

$$
\mathrm{d}_{(\mathrm{A}, \mathrm{B})}=\left[\sum_{\mathrm{i}=1}^{0}\left(\mathrm{X}_{\mathrm{i}(\mathrm{A})}-\mathrm{X}_{\mathrm{i(B)}}\right)^{2}\right]^{1 / 2}
$$

em que $d(A, B)$ é a medida de distância euclidiana da observação A e $\mathrm{B}$, sendo i o indexador das variáveis. Se a distância euclidiana for próxima a zero, significa que os objetos comparados são similares. Por fim, agrupam-se os sujeitos aos clusters cujos centróides se encontram mais próximos. 
É comum nas análises em ciências sociais aplicadas, a exemplo da administração e economia, dar nomes a cada agrupamento de acordo com suas características. É comum realizar também uma análise descritiva comparativa, para a validação dos agrupamentos, tomando como referência as variáveis selecionadas.

A nomeação dos grupos deste trabalho foi estabelecida a posteriori, pois, inicialmente, realizou-se uma comparação entre os agrupamentos resultantes e uma variável $W$ construída a partir de outras quatro variáveis, utilizando a técnica do balanço perguntado, abordada por Kassai e Kassai (2001).

A construção da variável problema de liquidez $W$ surgiu a partir da análise da composição de quatro variáveis dicotômicas, denominadas $V_{i}(1 \leq i \leq 4)$. As variáveis $V_{i}$ assumiram os valores $V_{i}=1$ nas seguintes condições: empresários que citaram possuir falta de capital de giro $\left(V_{1}\right)$, endividamento de curto prazo superior a $90 \%\left(V_{2}\right)$, não-provisionamento para falta de caixa $\left(V_{3}\right)$ e ciclos de caixa superiores a 60 dias $\left(V_{4}\right)$. A existência de problemas de liquidez foi convertida para uma escala dicotômica, em que $W=1$ representou a existência de problemas de liquidez, para somatório de $V_{i} \geq 2$, e $W=0$ representou a inexistência de risco de liquidez, para somatório de $V_{i}<2$. Esse procedimento estabeleceu dois grupos de referência para análise neste estudo: empresas com risco de liquidez e sem risco de liquidez. Em razão deste procedimento, aproximadamente, $43 \%$ das empresas foram classificadas com risco de liquidez.

Após estabelecimento dos agrupamentos, realizou-se o teste do Qui-Quadrado $\left(\chi^{2}\right)$ entre os três grupos resultantes da análise de cluster e a variável risco de liquidez $(W)$. Com teste significativo, constatou-se que os agrupamentos diferenciam-se quanto ao risco de liquidez $(W)$, possibilitando a nomeação dos grupos resultantes em: alto risco, médio risco e baixo risco, respectivamente para os grupos 1,2 e 3 .

\section{RESULTADOS}

A análise fatorial possibilitou a extração dos fatores, relacionados às características gerais das empresas e àquelas associadas, especificamente, à gestão de capital de giro. $\mathrm{Na}$ Tabela 1 é possível visualizar as estatísticas descritivas das variáveis utilizadas nessa análise fatorial. Por meio do teste de Bartlett, foi possível inferir a significância global do modelo a $1 \%$ de probabilidade.

Tabela 1- Variáveis utilizadas na análise fatorial

\begin{tabular}{l|cccc}
\hline & Mínimo & Máximo & Média & Desvio-padrão \\
\hline Tempo de existência & 1,00 & 81,00 & 11,05 & 11,33 \\
\hline Número de empregados & 0,00 & 33,00 & 3,43 & 3,71 \\
\hline Grau de investimento & 0,00 & 5,00 & 1,70 & 1,41 \\
\hline Vendas a prazo & 0,00 & 100,00 & 38,94 & 27,90 \\
\hline Contas a receber & 0,00 & 95,00 & 28,46 & 21,68 \\
\hline Nível de conhecimento sobre administração financeira & 1,00 & 5,00 & 4,52 & 2,70 \\
\hline Tempo de experiência & 0,00 & 65,00 & 9,65 & 10,27 \\
\hline Ciclo operacional & 0,00 & 410,00 & 73,03 & 64,31 \\
\hline Ciclo de caixa & $-90,00$ & 365,00 & 40,37 & 62,70 \\
\hline Faturamento anual & $1.200,00$ & $2.400 .000,00$ & $225.217,11$ & $345.416,64$ \\
\hline Escolaridade & 1,00 & 7,00 & 4,01 & 1,49 \\
\hline Fonte: resultados da pesquisa & & & &
\end{tabular}

Fonte: resultados da pesquisa.

A análise fatorial resultou na extração de quatro fatores com raiz característica (eigenvalues) maior que um (1), que em conjunto, respondem por $63,04 \%$ da variância total dos dados, conforme se observa na Tabela 2. Segundo Hair (2005), em ciências sociais - onde 


\section{INVESTIGAÇÃO DOS FATORES CONDICIONANTES DO CAPITAL DE GIRO EM MICRO E PEQUENAS EMPRESAS: UMA ABORDAGEM POR GRUPOS ESTRATÉGICOS}

as informações geralmente são menos precisas - uma solução que explique $60 \%$ da variância total é considerada satisfatória.

Tabela 2 - Caracterização dos fatores extraídos pelo método dos componentes principais

\begin{tabular}{c|ccc}
\hline Fator & Raiz característica & Variância explicada pelo fator (\%) & Variância acumulada (\%) \\
\hline 1 & 2,379 & 19,823 & 19,823 \\
\hline 2 & 1,942 & 16,183 & 36,006 \\
\hline 3 & 1,756 & 14,631 & 50,637 \\
\hline 4 & 1,489 & 12,405 & 63,042 \\
\hline
\end{tabular}

Fonte: resultados da pesquisa.

Em razão da análise das cargas fatoriais correspondentes aos coeficientes de correlação entre a variável i e o fator $\mathrm{j}$, após rotação ortogonal pelo método VARIMAX, foi possível classificar quatro fatores, interpretados a partir do ponto de vista da gestão de capital de giro, e defini-los conforme a representação homogênea de cada um. Dessa forma, os fatores receberam a seguinte nomenclatura: atividade; porte e conhecimento; vendas a prazo; e experiência (Tabela 3 ).

Tabela 3 - Matriz fatorial após rotação ortogonal4

\begin{tabular}{|c|c|c|c|c|}
\hline \multirow{2}{*}{ Variáveis } & \multicolumn{4}{|c|}{ Componentes rotacionados } \\
\hline & Fator 1 & Fator 2 & Fator 3 & Fator 4 \\
\hline Tempo de existência & & & & 0,872 \\
\hline Número de empregados & & 0,672 & & \\
\hline Grau de investimento & & 0,658 & & \\
\hline Vendas a prazo & & & 0,772 & \\
\hline Contas a receber & & & 0,791 & \\
\hline Nível de conhecimento sobre ADM financeira & & 0,543 & & \\
\hline Tempo de experiência & & & & 0,860 \\
\hline Ciclo operacional & 0,954 & & & \\
\hline Ciclo de caixa & 0,939 & & & \\
\hline Faturamento anual & & 0,580 & & \\
\hline Escolaridade & & 0,651 & & \\
\hline
\end{tabular}

Fonte: resultados da pesquisa

\section{Fator 1 - Atividade}

Este fator, formado pelas variáveis "ciclo operacional" e "ciclo de caixa", caracteriza os prazos de atividades operacionais e financeiros das empresas. Como é formado pelos ciclos de atividades (períodos de realização de ciclos de operacionais e de caixa), este fator foi renomeado simplesmente como "atividade" para facilitar sua retomada no decorrer do texto. Como citado por Souza (2007) e Pereira Filho (1998), o risco de liquidez aumenta para maiores prazos de atividade, principalmente para o ciclo de caixa, que é o principal indicador do tempo em que o caixa da empresa fica imobilizado. A boa política de capital de giro é elaborada para minimizar o tempo entre desembolsos de caixa com materiais e recebimentos das vendas, pois, quanto menor o ciclo de caixa, melhor a liquidez da empresa.

Da mesma forma, o aumento do ciclo operacional provoca aumentos no ciclo de caixa, visto que se torna necessário maior financiamento por parte dos fornecedores para mantê-lo no mesmo patamar. Chér (1990) afirmou que o efeito sanduíche coloca as MPEs em uma

\footnotetext{
${ }^{4} \mathrm{O}$ teste de confiabilidade interna de constructos, Alfa de Crombach, mostrou um valor de 96,4\% para o Fator 1, 49,4\% para o Fator 2, 67,9\% para o Fator 3 e 75,6\% para o Fator 4. Para a realização desse teste, as variáveis da Tabela 3 foram transformadas em escores $\mathrm{z}$, no intuito de obter maior uniformidade dos dados.
} 
situação de desvantagem para realizar negociações com fornecedores. Esse raciocínio pode ser estendido à negociação dos prazos de pagamento, no qual dificilmente as MPEs conseguirão elevar esse prazo na mesma proporção de um aumento do ciclo operacional, por causa do maior poder de barganha do fornecedor. Isso acarreta o aumento do ciclo de caixa e, desse modo, do risco de liquidez.

\section{Fator 2 - Porte e conhecimento}

Este fator, formado pelas variáveis "número de empregados", "faturamento anual", "grau de investimento" e "nível de conhecimento sobre administração financeira", permite dimensionar o porte e, ao mesmo tempo, o conhecimento dos dirigentes das empresas, desta forma recebendo a nomenclatura "porte e conhecimento" para retomada do fator durante o texto. Nem sempre a análise fatorial o grupo de variáveis tem sentido, sendo apenas resultado de comportamentos estatísticos das variáveis. Portanto, após o procedimento é realizada a validação teórica, buscando evitar relações de natureza espúria. Porém, empresas com maior porte e nível de conhecimento tenderiam a ter menos problemas de capital de giro em razão da provável existência de maior organização na administração da empresa e maior capacitação dos proprietários.

Matias e Lopes Junior (2002) e Monteiro (2002) citaram sobre a dificuldade vivenciada pela MPEs com o despreparo gerencial dos proprietários. Além disso, a falta de políticas de recursos humanos dificulta a contratação de pessoal qualificado para suprir a carência de conhecimento dos dirigentes. Isso torna o controle das atividades gerenciais dessas empresas baseado em experiências vividas pelos administradores, com previsões feitas ao acaso, acarretando desempenho inadequado nas questões gerenciais, principalmente no tocante às atividades financeiras de curto prazo, em que há necessidade do conhecimento do empresário para analisar relatórios financeiros, bem como delegar essas atividades para pessoal capacitado na falta de preparo para isso. É nessa base que se sustenta a importância do conhecimento dos proprietários na administração de curto prazo.

O conhecimento pode ser considerado uma variável atrelada ao porte da empresa já que empresas com maior faturamento e maior número de empregados necessitam de maior organização, e as complexidades dos processos organizacionais exigem maior conhecimento dos dirigentes.

\section{Fator 3 - Vendas a prazo}

Este fator é formado pelas seguintes variáveis: "vendas a prazo" e "contas a receber" e para simplificar a retomada no texto, esse fator será nomeado simplesmente como "vendas a prazo". Presume-se que as empresas com maior nível deste fator tenham mais problemas de liquidez, pois o investimento em caixa seria reduzido por causa do maior volume de duplicatas a receber. Sabe-se que os direitos da conta de duplicatas a receber correm o risco de não serem quitados pelo cliente, prejudicando, principalmente, a liquidez seca da empresa. Para evitar este tipo de risco, segundo Chér (1990), essas empresas devem evitar a manutenção de maus pagadores.

Menezes e Souza (2007) argumentam que a decisão ao nível de vendas e conseqüente nível de receitas para um determinado período relevante de planejamento deve fazer parte do conjunto de estratégias da empresa que deseje prosperidade relevante. A empresa deve estabelecer o nível adequado de caixa para pagar suas contas, o nível aplicado em estoques para manter as vendas e o crédito concedido ao cliente. O desequilíbrio dos níveis de estoques e crédito pode reduzir desnecessariamente o nível de caixa, impossibilitando a empresa de quitar suas dívidas de curto prazo. 


\section{Fator 4 - Experiência}

Este fator é formado pelas seguintes variáveis: "tempo de existência" e "tempo de experiência", recebendo dessa forma o nome "experiência" na retomada do texto. Espera-se que as empresas com maior média para este fator tenham menor risco de liquidez, em razão da experiência acumulada ao longo dos anos. Isso possui relação direta com a teoria da curva de aprendizagem citada por Farghal e Everett (1997), em que ao longo do tempo as empresas ganham em conhecimento, que auxilia na redução de problemas e, nesse ponto, começa-se a utilizar as curvas de aprendizagem. Elas demonstram a evolução, ou seja, a diminuição do tempo gasto para a execução do mesmo processo. Isso acontece em decorrência do sucessivo aperfeiçoamento na execução do trabalho e do efeito aprendizado. Juntamente com outras técnicas de controle de custos e tempo, a curva de aprendizagem pode ser uma ferramenta útil, predizendo o desempenho futuro de atividades repetitivas onde o efeito aprendizado está presente. $\mathrm{O}$ fator experiência possui grande importância para complementar a falta de preparo gerencial dos dirigentes das empresas, conforme Matias e Lopes Junior (2002) e Monteiro (2002).

\section{2 - Análises dos grupos}

A análise de agrupamento, para complementação da análise fatorial, resultou em grupos diferenciados de empresas. $\mathrm{Na}$ Tabela 4, observam-se as estatísticas descritivas dos fatores, bem como percebem-se as similaridades e diferenças entre os grupos.

Tabela 4 - Estatística descritiva - método de K-means

\begin{tabular}{c|ccccc}
\hline Grupos & Fatores & Mínimo & Máximo & Média & Desvio-padrão \\
\hline \multirow{5}{*}{1} & Atividade & 0,9080 & 4,9606 & 2,0699 & 1,0956 \\
\cline { 2 - 5 } & Porte e conhecimento & $-0,9783$ & 2,5549 & 0,3740 & 0,9537 \\
\cline { 2 - 5 } & Práticas de vendas & $-1,9888$ & 2,6510 & 0,1343 & 1,2014 \\
\cline { 2 - 6 } & Experiência & $-1,3352$ & 0,2956 & $-0,3690$ & 0,4923 \\
\hline \multirow{5}{*}{2} & Atividade & $-1,1995$ & 1,2690 & $-0,0381$ & 0,6808 \\
\cline { 2 - 6 } & Porte e conhecimento & $-1,6127$ & 3,4680 & $-0,0739$ & 1,2612 \\
\cline { 2 - 6 } & Práticas de vendas & $-2,0043$ & 1,9017 & 0,0320 & 0,9685 \\
\cline { 2 - 6 } & Experiência & 0,6138 & 3,8063 & 1,6494 & 0,9042 \\
\hline \multirow{5}{*}{3} & Atividade & $-1,7475$ & 0,8458 & $-0,3373$ & 0,5374 \\
\cline { 2 - 5 } & Porte e conhecimento & $-2,0212$ & 3,3253 & $-0,0424$ & 0,9188 \\
\cline { 2 - 5 } & Práticas de vendas & $-1,7880$ & 2,8023 & $-0,0315$ & 0,9788 \\
\cline { 2 - 5 } & Experiência & $-1,3287$ & 0,6510 & $-0,3954$ & 0,4969 \\
\hline
\end{tabular}

Fonte: resultados da pesquisa.

Como citado na metodologia, a nomeação e caracterização dos grupos baseou-se na comparação destes grupos com a variável risco de liquidez $(W)$. O resultado do teste do QuiQuadrado pode ser visualizado na Tabela 5. De acordo com os resultados do teste, pode-se perceber que $70 \%$ das empresas do grupo 1 estão classificadas no grupo com risco de liquidez. Por outro lado, $61,3 \%$ das empresas do grupo 3 estão classificadas sem risco de liquidez. Percebe-se que o grupo 2 ficou em posição intermediária, com 57,6\% das empresas classificadas com risco e $42,4 \%$ classificadas sem risco. Com esses resultados, foi possível nomear os agrupamentos da seguinte forma: alto risco, médio risco e baixo risco, sendo estes nomes atribuídos, respectivamente, aos grupos 1, 2 e 3.

Tabela 5 - Qui-quadrado entre os grupos e risco de liquidez

\begin{tabular}{c|cc}
\hline \multirow{2}{*}{ Grupos } & \multicolumn{2}{|c}{ Problemas de capital de giro } \\
\cline { 2 - 3 } & Não & Sim \\
\hline 1 & $30,0 \%$ & $70,0 \%$ \\
\hline
\end{tabular}

Revista de Negócios, ISSN 1980-4431, Blumenau, v. 13, n. 3, p. 51 - 66, Julho/Setembro 2008. 60 


\begin{tabular}{c|cc}
\hline 2 & $57,6 \%$ & $42,4 \%$ \\
\hline 3 & $61,3 \%$ & $38,7 \%$ \\
\hline$\chi^{2}=\mathbf{2 6 , 7 6 8} ; \mathbf{p}=\mathbf{0 , 0 3 4 8}$ &
\end{tabular}

$\chi^{2}=26,768 ; p=0,0348$

Fonte: resultados da pesquisa.

A combinação dos escores fatoriais possibilitou a caracterização dos três grupos e a identificação dos principais condicionantes do risco de liquidez nas empresas. Isso vai ao encontro das considerações de Chrisman et al., (1988) em que uma classificação deve possibilitar a diferenciação, identificação e generalização. Neste estudo, foi possível diferenciar os grupos quanto ao risco de liquidez. Essa diferenciação possibilitou a nomeação dos grupos e a generalização para as inferências sobre problemas de liquidez.

Cada grupo possui características semelhantes entre si e divergências entre os grupos, como ocorre em todo agrupamento, segundo Athanassopoulos (1995). Isso possibilitou a identificação de condicionantes do risco de liquidez das empresas, pois, provavelmente, os grupos de alto e baixo risco possuem escores fatoriais antagônicos que evidenciam aspectos da gestão financeira de curto prazo, o que propicia o aumento desse tipo de risco.

A Tabela 6 possibilita visualizar o dimensionamento de cada fator para os agrupamentos do estudo. Percebe-se que o grupo 1 possui maiores escores para três fatores, enquanto o grupo 3 possui menores escores, também, para três fatores. O grupo 2 possui dois escores intermediários: um maior e outro menor.

Tabela 6 - Dimensionamento dos fatores em cada grupo

\begin{tabular}{c|ccc}
\hline Fatores & Grupo 1 & Grupo 2 & Grupo 3 \\
\hline Atividade & Alto & Médio & Baixo \\
\hline Porte e conhecimento & Alto & Baixo & Médio \\
\hline Práticas de vendas & Alto & Médio & Baixo \\
\hline Experiência & Médio & Alto & Baixo \\
\hline
\end{tabular}

Fonte: resultados da pesquisa.

Para corroborar a análise dos agrupamentos, foram acrescentadas três variáveis que podem auxiliar na discriminação dos grupos quanto às características da gestão do capital de giro (Tabela 7). Essas variáveis foram coletadas na entrevista, mas não foram incluídas na análise fatorial pela falta de correlação. As variáveis incluídas foram: o percentual de capital próprio utilizado na abertura da empresa e a porcentagem que o caixa representa no total do ativo circulante. As médias dessas variáveis foram transformadas em escores $Z$, a fim de obter homogeneidade com os escores obtidos na análise fatorial.

Tabela 7 - Variáveis complementares à análise fatorial

\begin{tabular}{c|lcccc}
\hline Grupos & & Mínimo & Máximo & Média & Desvio-padrão \\
\hline \multirow{3}{*}{1} & Capital próprio para abertura da empresa & 0,41 & 0,41 & 0,4107 & 0,0000 \\
\cline { 2 - 6 } & Porcentagem de caixa & $-1,22$ & 1,47 & $-0,4363$ & 0,7352 \\
\cline { 2 - 6 } & Capital próprio para abertura da empresa & $-1,75$ & 0,41 & 0,3075 & 0,4029 \\
\cline { 2 - 6 } & Porcentagem de caixa & $-1,22$ & 1,92 & $-0,0217$ & 0,6627 \\
\cline { 2 - 6 } 3 & Capital próprio para abertura da empresa & $-3,90$ & 0,41 & $-0,1543$ & 1,1516 \\
\cline { 2 - 6 } & Porcentagem de caixa & $-1,22$ & 3,27 & 0,0793 & 1,0974 \\
\hline
\end{tabular}

Fonte: resultados da pesquisa.

\section{Grupo 1 - Alto risco}

Este grupo é formado por $12 \%$ das empresas. Possui as maiores médias de escores para os fatores "atividade", "porte e conhecimento" e "vendas a prazo". Como esperado, os fatores atividade e práticas vendas foram maiores neste grupo, de acordo com a discussão na seção de análise fatorial. O fator "atividade" mostra que essas empresas possuem maiores ciclos operacionais e de caixa, desencadeando a possibilidade de maior risco de liquidez em 
razão do aumento da imobilização do caixa. Quanto ao fator "vendas a prazo", foi mencionado que seu aumento reduz a liquidez da empresa, tendo em vista que os recursos que poderiam ser aplicados em caixa são transferidos para a conta duplicatas a receber. Por outro lado, esperava-se que o escore do fator "porte e conhecimento" fosse menor para este grupo, tendo em vista sua associação com menor risco de liquidez. Assim, neste estudo, percebe-se que as empresas de maior porte e conhecimento teriam maior potencial para problemas de liquidez. Devido ao maior porte, essas empresas podem possuir maior reputação no mercado e maior oferta de crédito, que por sua vez pode ser umas das explicações do aumento do risco de liquidez para maiores escores do fator "porte e conhecimento".

Outra característica deste grupo é sua predominante composição por empresas com maiores médias de utilização de capital próprio na abertura do negócio (Tabela 7). Segundo informações do último relatório Global Entrepreneurship Monitor - GEM (2007), que discorre sobre o empreendedorismo brasileiro, sabe-se que este se faz, fundamentalmente, a partir de recursos próprios dos empreendedores, com apoio substancial de amigos e parentes.

Os montantes utilizados para abertura dos negócios citados pelo referido relatório, em geral, são muito baixos, já que $55 \%$ dos empreendedores afirmam ser menor do que $\mathrm{R} \$$ $2.000,00$ a quantia necessária para abertura de seu negócio. É importante salientar que pouco mais de um terço destes afirmam não necessitar de recurso algum para iniciar o empreendimento, o que denota a simplicidade na concepção dos empreendimentos e a dificuldade do empreendedor em valorizar os recursos necessários à operação da atividade (BOSMA et al., 2008; PASSOS et al., 2008).

Nesse sentido, com esgotamento dos recursos próprios, essas empresas carecem de recursos para investimento nas suas atividades operacionais. Aos empresários resta captar recursos no mercado, pois, de acordo com as proposições disponíveis na literatura, a teoria da pecking order $^{5}$ argumenta que as decisões de financiamento ocorrem de acordo com uma ordem de preferências, em que primeiro a firma financia-se com recursos internos, depois recorre ao endividamento externo (MYERS, 1984; MYERS; MAJLUF, 1984; MORAES; RHODEN, 2005). Como é fato que o pequeno empresário possui financiadores restritos ao seu tipo de negócio, o aumento do risco de liquidez é evidente nesse caso.

\section{Grupo 2 - Médio risco}

Este grupo, formado por $19 \%$ da amostra, apresentou escores intermediários para os fatores "atividade" e "vendas a prazo". No entanto, apresentou o maior escore para o fator "experiência" e o menor para o fator "porte e conhecimento"; o que possibilita inferir que o nível de experiência e a consolidação no mercado são importantes fatores condicionantes do risco de liquidez, mas por si, não são capazes de determinar a redução desse nível.

Pela Tabela 7, pode-se observar que este grupo possui escores intermediários para o capital próprio utilizado na abertura da empresa e para a porcentagem de caixa na composição do ativo circulante.

\section{Grupo 3 - Baixo risco}

Este grupo é composto por $69 \%$ das empresas da amostra. Ao contrário do grupo 1, este possui a menor média para o fator "atividade", assim como a menor média de escores para o fator "vendas a prazo". Constata-se que estes fatores são importantes condicionantes do risco de liquidez dessas empresas, uma vez que foram opostos para grupos de baixo e alto risco.

\footnotetext{
${ }^{5}$ Teoria de Hierarquia de Fontes.
} 
Por outro lado, esperava-se que este grupo apresentasse os maiores escores para os fatores "porte e conhecimento" e "experiência", tendo em vista que estão associados a menor risco de liquidez, como já discutido. Todavia, como observado, esses resultados foram obtidos para o grupo de alto risco, o que parece corroborar que o tempo de experiência, por si, não é capaz de explicar a redução no nível de risco de liquidez. Aliás, já se discute a tempos na administração que tempo de mercado não é uma excelente proxy para experiência empresarial, uma vez que existem empresas que operam ineficientemente por anos, em razão de aspectos já discorridos, a exemplo de operarem em escala ou ganhos pouco estimulantes à concorrência ou em setores que apresentam barreiras a entrada de novas organizações. Além disso, como discutido para o Grupo 1, maior porte e tempo no mercado podem estar associado a maior oferta de crédito e desta forma a extensão do ciclo operacional, aumentando a possibilidade de risco de liquidez para essas empresas.

$\mathrm{Na}$ Tabela 7, é possível perceber que este grupo é composto pelas empresas com menor utilização de capital próprio na abertura do empreendimento. Mesmo apresentando menor complexidade, segundo Chér (1990), as MPEs necessitam ponderar seus financiamentos de curto e longo prazo para manter o equilíbrio financeiro. Então, a escolha do nível de investimento adequado que não esgote os recursos próprios do empreendedor tornase viável, para que este mantenha reservas pessoais até quando a própria empresa conseguir gerar esses excedentes. Isso reduz o risco de liquidez por que passam aquelas empresas que não possuem recursos não provisionados pelo empresário.

Por outro lado, a Tabela 7 mostra que este grupo é formado por empresas com maior porcentagem de caixa. Como citado por Serrasqueiro e Raposo (2002) e Matarazzo (2003), a manutenção de reservas de caixa proporciona melhor liquidez para prováveis oportunidades e contingências associadas ao curto prazo. Essa diferenciação já era esperada, já que, quanto maior a disponibilidade de caixa, menores seriam os problemas de liquidez. Além disso, é essencial que a empresa tenha ativos em moeda ou quase moeda suficientes para obter vantagens no mercado de curto prazo.

\section{CONCLUSÃO}

As análises utilizadas neste estudo possibilitaram a identificação de três agrupamentos distintos, referentes às características da gestão de capital de giro nas MPEs, na região em estudo. A partir da formação desses grupos, foi possível caracterizar, cada um independentemente, evidenciando que as MPEs possuem diferentes estratégias na gestão financeira de curto prazo, o que possibilitou identificar alguns condicionantes dos problemas de capital de giro nessas empresas.

É notório que as MPEs são bastante heterogêneas, tanto que atualmente existem dificuldades em classificá-las. Essa heterogeneidade também é encontrada na gestão de curto prazo dessas empresas, em razão das diferenças nos escores obtidos entre os agrupamentos para alguns fatores e variáveis condicionantes. A relevância dessas diferenças foi comprovada pelos procedimentos estatísticos de agrupamento utilizados neste estudo.

Embora se observasse um grupo com baixo risco de liquidez, fica evidente a importância da gestão financeira de curto prazo na região em estudo, visto que a manutenção de uma correta gestão está longe de ser unânime, em razão da presença de aproximadamente $30 \%$ das empresas classificadas nos grupos de médio e alto risco de liquidez. A identificação de empresas com melhores práticas na gestão financeira de curto prazo pode ser um instrumento para aplicação nas empresas dos agrupamentos de médio e alto risco de liquidez.

A identificação de fatores condicionantes da liquidez, como ciclo operacional, ciclo de caixa, crédito concedido aos clientes, porcentagem de caixa, entre outros, possibilita 
intervenções nas MPEs para melhoria da gestão do capital de curto prazo, com adoção das melhores práticas de gestão para esses condicionantes, além da introdução de políticas públicas e privadas diferenciadas no estímulo e fomento das atividades dessas organizações que representam importante parcela da economia nacional. A identificação do risco de liquidez nessas empresas é um relevante passo para redução dos enormes indicadores de mortalidade das MPEs no País. Devido aos modestos, porém importantes resultados alcançados com este trabalho, sugere-se aos cientistas e pesquisadores da área, estudos mais abrangentes, buscando identificar grupos de empresas e seus condicionantes de problemas de liquidez, ampliando a área geográfica, visando isolar efeitos geográficos.

\section{Referências}

ATHANASSOPOULOS, A.D. Goal programming and Data Envelopment Analysis (GoDEA) models for multi-level multi-unit organizations: an application to Greek local authorities. European Journal of Operational Research, v. 87, p. 535-550, 1995.

ATHANASSOPOULOS, A.D.; BALLANTINE, J. Ratio and frontier analysis for assessing corporate performance: the case of grocery industry in the UK. Journal of the Operational Research Society, v. 46, p. 427-440, 1995.

BARNEY, J.; HOSKISSON, R. Strategic groups: untested assertions and research proposals. Managerial and Decision Economics, v. 11, n. 3, p. 187-198, 1990.

BOSMA, N.; JONES, K.; AUTIO, E.; LEVIE, J. Global Entrepreneurship Monitor. Babson College London Business School. Babson Park, MA, US London, UK, p.66. 2008.

BRAGA, R., NOSSA, V.; MARQUES, J.A.V.C. Uma proposta para a análise integrada da liquidez e rentabilidade das empresas. Revista Contabilidade \& Finanças, edição especial, p. 51-64, jun. 2004.

CHÉR, R. A gerência das pequenas e médias empresas: o que saber para administrá-las. São Paulo: Maltese, 1990.

CHRISMAN, J. J.; HOFER, C. W.; BOULTON, W. R. Toward a system for classifying business strategies. Journal Academy of Management Review, v.13, n.3, p.413-428, 1988.

DAY, D.; LEWIN, A.; LI, H. Strategic leaders or strategic groups: a longitudinal data envelopment analysis of the US brewing industry. European Journal of Operational Research, v. 80, n. 3, p. 619-638, 1995.

DUYSTERS, G.; HAGEDOORN, J. Strategic groups and inter-firm networks in international high-tech industries. Journal of Management Studies, n. 32, p. 359-380, 1995.

FARGHAL, Sherif H.; EVERETT, John G. Learning curves: accuracy in predicting future performance. Journal of Construction Engineering and Management, v. 123, p. 41-45, 1997.

FIEGENBAUM, A.; THOMAS, H. Strategic groups and performance: the U.S. insurance industry, 1970-84. Strategic Management Journal, v. 11, n. 3, p. 197-215, 1994.

GAZZONI, E. I. Fluxo de caixa- ferramenta de controle financeiro para pequena empresa. 2003. 96 f. Dissertação (Mestrado em Engenharia de Produção) - Universidade Federal de Santa Catarina, Florianópolis. Disponível em: $<$ http://teses.eps.ufsc.br/defesa/pdf/9318.pdf $>$. Acesso em: 26 jun. 2006. 
GORDON, M., MILNE, G. Selecting the dimensions that define strategic groups: a novel market driven approach. Journal of Managerial Issues, v. 11, n. 2, p. 213-233, 1999.

HAIR, J. F. Análise multivariada de dados. Porto Alegre: Bookman, 2005. 593 p.

HOPP, J.C.; LEITE. H.P. O mito da liquidez. Revista de Administração de Empresas, São Paulo, v. 29, n.4, p. 63-69, out / dez. 1989.

KASSAI, J.R.; KASSAI, S. Balanço perguntado: solução para as pequenas empresas. In: CONGRESSO BRASILEIRO DE CUSTOS, 8., 2001, Rio Grande do Sul. Anais... São Leopoldo, 2001.

KUMAR, R.; THOMAS, H.; FIEGENBAUM, A. Strategic groupings as competitive benchmarks for formulating future competitive strategy: a modeling approach. Managerial \& Decision Economics, v. 11, n. 2, p. 99-109, 1990.

LAWLESS, M.; ANDERSON, P. Generational technological change: the effects of innovation and local rivalry on performance. Academy of Management Journal, p. 645-664, 1996.

LEMES JUNIOR, A. C. B.; RIGO C. M, et al. Administração financeira: princípios, fundamentos e práticas trabalhistas. Rio de Janeiro: Elsevier. 2005. 547 p.

MAROCO, J. Análise estatística. Lisboa: Sílabo, 2003. 508 p.

MATIAS, G. A.; LOPES JR., F. Administração financeira nas empresas de pequeno porte. São Paulo: Manole, 2002.

MENEZES, E. C.: SOUSA, A. F. Estratégia, crescimento e a administração do capital de giro. Caderno de Pesquisas em Administração, São Paulo, v.2, $\mathrm{n}^{\circ}$ 5, 20 Sem/1997. Disponível em: <http://www.eac.fea.usp.br>. Acesso em: 29 jun. 2003.

MONTEIRO, A. A. S. M. Fluxos de caixa e capital de giro: uma adaptação do modelo de Fleuriet. In: SEMINÁRIO DE CONTABILIDADE E CONTROLADORIA, 2.; 2003, São Paulo. Anais... São Paulo: FEA-USP, 2002. Disponível em: <http://www.eac.fea.usp.br> Acesso em: 04 maio 2003.

MORAES, E. G.; RHODEN, M. I. S. Determinantes da estrutura de capital das empresas listadas na Bovespa. In: ENCONTRO NACIONAL DOS PROGRAMAS DE PÓSGRADUAÇÃO EM ADMINISTRAÇÃO, 29, 2005, Brasília, Anais ... Brasília: EnANPAD, 2005.

MYERS, S.C. The capital structure puzzle. Journal of Finance, Chicago: American Finance Association, v.39, n.3, Jul.1984.

MYERS, S.C.; MAJLUF, N. Corporate financing and investment decisions when firms have informations that investors do not have. Journal of Financial Economics, vol. 13, p. 187$221,1984$.

PASSOS, C. A. K.; FELIX, J.C; GRECO, S. M. S.S. Empreendedorismo no Brasil: 2007. Instituto Brasileiro de Qualidade e Produtividade, p.171. 2008.

PEREIRA FILHO, A. D. O modelo dinâmico de gestão financeira de empresa: procedimentos de operacionalização. Revista Contabilidade Vista \& Revista, Belo Horizonte, v. 9, n.4, p.12-22, dez. 1998. 
RESNIK, P. A bíblia da pequena empresa: como iniciar com segurança sua pequena empresa e ser muito bem sucedido. São Paulo: McGraw-Hill, 1990.

SCHEFCZYK, M. Operational performance of airlines: an extension of traditional measurement paradigms. Strategic Management Journal, n. 14, p. 301-317, 1993.

SCHENDEL, D.E.; HOFER, C.W. Strategic management: a new view of business policy and planning. Boston, MA: Little, Brown, 1979.

SERRASQUEIRO, Z. M. S.; RAPOSO, M. L. B. Capital Budgeting Practices: An Empirical Approach to Portuguese SMEs, Conference Proceedings, RENT XVI- Research Entrepreneurship and Small Business, 16th Workshop, November 21-22, Barcelona, Spain, 2002.

SERVIÇO BRASILEIRO DE APOIO ÀS MICRO E PEQUENAS EMPRESAS -SEBRAE. Boletim estatístico de micro e pequenas empresas. Brasília: 2005. Disponível em: $<$ www.sebrae.com.br/br/mpe\%5Fnumeros/>. Acesso em: 20 fev. 2006.

Fatores condicionantes e taxa de mortalidade das micro e pequenas empresas. VOX POPULI. Agosto de 2007. 2007. Disponível em: $<$ www.sebrae.com.br $>$. Acesso em: 18 jan. 2008.

SOUZA, R.M. Avaliação de custo, volume e lucro em micro e pequenas empresas comerciais: um estudo de caso. 2007. 107 f. Dissertação (Mestre em Engenharia de Produção) - Universidade Federal de Itajubá, Itajubá. 